\title{
COMBINED SPINAL EPIDURAL VERSUS EPIDURAL ANAESTHESIA IN MAJOR SURGERIES
}

\author{
Manoj Kumar Upadhyay1, Apurva Agarwal2
}

${ }_{1}^{1}$ Associate Professor, Department of Anaesthesiology, GSVM Medical College, Kanpur.

2Professor, Department of Anaesthesiology, Government Medical College, Kannauj.

ABSTRACT
BACKGROUND
Combined spinal epidural anaesthesia is a comparatively recent innovation in the central neuraxial anaesthetic procedures. With
proper patient and needle selection, we believe that CSEA may offer advantages over both spinal and epidural anaesthesia for
outpatient surgery as well. Compared with spinal anaesthesia CSEA offers increased flexibility, because the duration of anaesthesia
can be extended using the epidural catheter. Combined spinal epidural anaesthesia may also provide a decreased duration of
anaesthesia by allowing administration of the minimal intrathecal dose required to establish the initial level of surgical
anaesthesia. This is made possible because of the confidence afforded by the continuous techniques as a backup. Compared with
epidural anaesthesia alone, CSEA has a shorter onset and virtually eliminates most of the serious complications of epidural and
spinal anaesthesia.

\section{MATERIALS AND METHODS}

This prospective, randomised, controlled study was conducted at a tertiary care hospital incorporating 60 patients. Patients were divided into two groups using computer-generated random number table. In Group-I of 30 patients CSEA was used, while in Group-II of 30 patients EA was used.

\section{RESULTS}

The demographic profile of the patients in both groups was comparable with regards to age, weight and height. In Group-I the mean dose of intrathecal, extradural and total Bupivacaine was $11.07 \pm 1.38 \mathrm{mg}, 15.63 \pm 3.13 \mathrm{mg}$ and $28.60 \pm 3.74 \mathrm{mg}$ respectively. In CSEA group of 30 patients the CSE needle was inserted successfully in 93.4\%, of which in about 92.8\% cases of extradural catheter was placed successfully, while in EA group the epidural needle was inserted successfully in $93.3 \%$, which in $89.3 \%$ cases the extradural catheter was placed successfully.

\section{CONCLUSION}

A statistically significant and progressive fall in pulse rate and blood pressure was noted in first 10 mins of combined spinal epidural anaesthesia group and in between 10 - 30 mins of epidural anaesthesia group and in between 10 - 30 mins of epidural anaesthesia group. This fall was noted because of autonomic nervous system blockade. In epidural anaesthesia group, the mean fall in blood pressure was between 20 - 30 mins and was comparatively more than in CSEA group.

\section{KEYWORDS}

Combined Spinal Epidural Anaesthesia, Epidural Anaesthesia, Regional Anaesthesia, Local Anaesthetic, Bupivacaine.

HOW TO CITE THIS ARTICLE: Upadhyay MK, Agarwal A. Combined spinal epidural versus epidural anaesthesia in major surgeries. J. Evolution Med. Dent. Sci. 2018;7(01):94-97, DOI: 10.14260/jemds/2018/21

\section{BACKGROUND \\ Major regional anaesthetic techniques practiced to date are} spinal and epidural anaesthesia for surgeries performed on lower half of the body, which are central neuraxial blocks. The use of regional anaesthesia in training programs is increased from $21.3 \%$ in 1980 to $29.8 \%$ in 1990 , primarily because of a two-fold increase in the use of epidural anaesthesia, Broadman LM et al. ${ }^{1}$

Combined spinal epidural anaesthesia is a comparatively recent innovation in the central neuraxial anaesthetic procedures. With proper patient and needle selection, we believe that CSEA may offer advantages over both spinal and epidural anaesthesia for outpatient surgery as well BT Shitzman et al. ${ }^{2}$ Compared with spinal anaesthesia CSEA offers increased

'Financial or Other Competing Interest': None.

Submission 09-11-2017, Peer Review 15-12-2017,

Acceptance 20-12-2017, Published 01-01-2018.

Corresponding Author:

Dr. Apurva Agarwal,

Professor, 8/48, Arya Nagar, Kanpur.

E-mail: drapurva.agarwal@gmail.com

DOI: $10.14260 /$ jemds/2018/21 flexibility, because the duration of anaesthesia can be extended using the epidural catheter, Holmstrom B et al. ${ }^{3}$

Combined spinal epidural anaesthesia may also provide a decreased duration of anaesthesia by allowing administration of the minimal intrathecal dose required to establish the initial level of surgical anaesthesia. This is made possible because of the confidence afforded by the continuous techniques as a backup. Compared with epidural anaesthesia alone, CSEA has a shorter onset and virtually eliminates most of the serious complications of epidural and spinal anaesthesia, Tadoori $\mathrm{P}$ et $\mathrm{al}^{4}$

CSEA combines benefits of certainty with a definite end point (appearance of CSF), Niinai $\mathrm{H}$ et al. ${ }^{5}$ This characteristic of spinal anaesthesia is combined with flexibility of continuous epidural anaesthesia. CSEA also provides a route for effective postoperative analgesia for local anaesthetic administration in the orthopaedic patients, Wakamatsu M et al. 6

\section{Objective of the Study}

The Purpose of our Study was to compare the Combined Spinal Epidural and Epidural Anaesthesia in Major Surgeries in Respect of- 
1. Onset and duration of sensory and motor blockade.

2. Degree if sensory and motor blockade achieved.

3. Doses of local anaesthetic (Bupivacaine in $\mathrm{mg}$ ) required.

4. Incidence of failure of the techniques.

5. Incidence of side effects and complications.

\section{MATERIALS AND METHODS}

\section{Design and Sampling}

Design- A prospective, randomised controlled study.

- Study Period- Two years.

- Sampling- All patients coming to hospital for elective surgeries from Kanpur and nearby districts were selected for the purpose of study.

\section{Sample Size}

Sample size was taken conveniently.

\section{Inclusion Criteria}

Patients aged $>18$ years and $<60$ years who gave consent to be the part of study.

\section{Exclusion Criteria}

1. Patient's refusal, 2. Allergy to local anaesthetics, 3. Patients on anticoagulant drugs, 4. Spinal deformities, 5. Cardiac patients, 6. Emergency surgeries.

\section{Ethical Issues}

Ethical Clearance was sought from Hospital Ethics Committee. Besides this,

1. Written consent was taken from patients participating in the study.

2. Confidentiality was maintained.

This prospective, randomised, double-blind study was conducted at a tertiary care hospital incorporating 60 patients. The patients were randomly allocated to one of the following two groups based on a computer-generated random number table. Informed consent preoperative evaluation, premedication and checking for sensitivity of local anaesthetic was done in every patient. All patients were preloaded with ringer lactate solution in doses of $10 \mathrm{~mL} / \mathrm{kg}$ and infused at a rate of $15 \mathrm{~mL} / \mathrm{kg} /$ hour. In Group- 1 of 30 patients CSEA was used, while in Group-II of 30 patients EA was used and extradural catheter was placed simultaneously for postoperative pain relief in both groups.

Onset and duration of sensory as well as motor blockade were noted. The degree of sensory block is graded as excellent, good, fair and poor, while the motor block was assessed according to the Bromage scale. The total duration of anaesthesia after the first dose of local anaesthetic and postoperative analgesia were noted. Intraoperative monitoring was done in every patient and complications were noted. For postoperative pain relief, $25 \mathrm{mg}$ of Bupivacaine and $50 \mathrm{mg}$ of Tramadol HCL were injected extradural in all patients. The anaesthesiologist performing the procedure and the study observer were blinded to the study groups.

Kolmogorov-Smirnov test was used to test the normality of the data. The qualitative data were expressed as number $(\%)$, while the continuous quantitative data as mean \pm standard deviation (SD) and the data was statistically analysed. The mean and standard deviation were derived for continuous variables with normal distribution. Chi-square test was used to compare the categorical variables and unpaired student t-test was used to analyse the continuous data between the two groups. Statistical analysis was performed using SPSS version 20.0 for windows (IBM Software Group, Chicago, IL 60606, USA). P-value at $<0.05$ was considered significant and at $<0.001$ was considered highly significant, while at $>0.05$ was considered not significant.

\section{RESULTS}

The mean age and sex ratio in Group-I, the mean dose of intrathecal, extradural and total Bupivacaine was $11.07 \pm$ $1.38 \mathrm{mg}, 15.63 \pm 3.13 \mathrm{mg}$ and $28.60 \pm 3.74 \mathrm{mg}$ respectively. In Group-II, the mean dose of extradural Bupivacaine was 90.90 $\pm 7.32 \mathrm{mg}$.

In CSEA group of 30 patients the CSE needle was inserted successfully in $93.4 \%$, of which in about $92.8 \%$ cases of extradural catheter was placed successfully. While in EA group the epidural needle was inserted successfully in $93.3 \%$, which in $89.3 \%$ cases the extradural catheter was placed successfully.

\begin{tabular}{|c|c|c|c|}
\hline Group & $\begin{array}{c}\text { Intrathecal 0.5\% } \\
\text { Bupivacaine } \\
\text { (Heavy) Dose (mg) }\end{array}$ & $\begin{array}{c}\text { Extradural 0.5\% } \\
\text { Bupivacaine } \\
\text { (isobaric) Dose (mg) }\end{array}$ & $\begin{array}{c}\text { Total } \\
\text { (mg) }\end{array}$ \\
\hline I & $11.07 \pm 1.38$ & $15.63 \pm 3.13$ & $\begin{array}{c}28.60 \pm \\
3.74\end{array}$ \\
\hline II & ---- & $90.90 \pm 7.32$ & $\begin{array}{c}90.90 \pm \\
7.32\end{array}$ \\
\hline \multicolumn{3}{|c|}{ Table 1. Mean Dose of Local Anaesthetic } \\
(Bupivacaine) in mg
\end{tabular}

In CSEA group the mean time for onset of action of sensory block was $3.16 \pm 0.875$ minute, while it was $18.46 \pm$ 3.78 minutes in EA group $(\mathrm{t}=20.9, \mathrm{p}=0.001)$. Similarly, the onset of motor block in CSEA group was $8.37 \pm 1.27$ minute, while in EA group it was $25.85 \pm 2.47$ minute $(\mathrm{t}=33.28$; $\mathrm{p}=0.0001)$.

\begin{tabular}{|c|c|c|c|c|c|}
\hline \multirow{2}{*}{} & & \multicolumn{2}{|c|}{ Group I } & \multicolumn{2}{c|}{ Group II } \\
\cline { 2 - 6 } & No. & \% & No. & \% \\
\cline { 2 - 6 } & 1st Attempt & 22 & 73.40 & 24 & 80.00 \\
\hline $\begin{array}{c}\text { Success of } \\
\text { Needle } \\
\text { Insertion }\end{array}$ & $\begin{array}{c}\text { More than } \\
\text { one attempt }\end{array}$ & 6 & 20.00 & 4 & 13.30 \\
\cline { 2 - 6 } & Failed & 2 & 6.60 & 2 & 6.70 \\
\hline $\begin{array}{c}\text { Success of } \\
\text { Catheter } \\
\text { Insertion }\end{array}$ & Successful & 26 & 92.80 & 25 & 89.30 \\
\cline { 2 - 6 } & Failed & 2 & 7.20 & 3 & 10.70 \\
\hline
\end{tabular}

Table 2. Success of Combined Spinal Epidural and Epidural Technique

The degree of sensory block noticed in CSEA group was excellent in $82.14 \%$ and good in $17.86 \%$, while in EA group it was excellent in $64.28 \%$, good in $7.14 \%$, fair in $14.29 \%$ and poor in $14.29 \%$.

\begin{tabular}{|c|c|c|c|c|}
\hline \multirow{2}{*}{} & \multicolumn{2}{|c|}{ Group I } & \multicolumn{2}{c|}{ Group II } \\
\cline { 2 - 5 } & Number & $\mathbf{\%}$ & Number & \% \\
\hline Excellent & 23 & 82.14 & 19 & 64.28 \\
\hline Good & 5 & 17.86 & 2 & 7.14 \\
\hline Fair & -- & -- & 4 & 14.29 \\
\hline Poor & -- & -- & 4 & 14.29 \\
\hline
\end{tabular}

Table 3. Degree of Sensory Block in Both Groups 
The degree of motor block which was assessed by Bromage scoring, complete (score 10) and almost complete (score 6) blockade was seen in 78.6\% of cases in CSEA group and in $64.6 \%$ of cases in EA group, while partial block (score 3 ) and no block (score 1) was noted in $21.4 \%$ of cases in CSEA group and $35.7 \%$ of cases in EA group $(\mathrm{t}=11.73$; $\mathrm{p}=0.0001)$.

\begin{tabular}{|c|c|c|c|c|}
\hline \multirow{2}{*}{ Bromage Scoring } & \multicolumn{2}{|c|}{ Group I } & \multicolumn{2}{c|}{ Group II } \\
\cline { 2 - 5 } & No & \% & No. & \% \\
\hline No Block (Score 1) & 3 & 10.7 & 4 & 14.3 \\
\hline Partial Block (Score 2) & 3 & 10.7 & 6 & 21.4 \\
\hline Almost Complete (Score 3) & 11 & 39.3 & 10 & 35.7 \\
\hline Complete (Score 4) & 11 & 39.3 & 8 & 28.6 \\
\hline Table 4. Degree of Motor Blockade in Both Groups \\
\hline
\end{tabular}

The mean duration of anaesthesia by first dose of local anaesthetic in CSEA group was $170.72 \pm 26.83$ minute, while that in EA group was $197.14 \pm 24.75$ minute.

\begin{tabular}{|c|c|c|c|c|}
\hline \multirow{2}{*}{$\begin{array}{c}\text { Time Interval } \\
\text { (Mins) }\end{array}$} & \multicolumn{2}{|c|}{ Group I } & Group II \\
\cline { 2 - 5 } & Number & $\mathbf{\%}$ & Number & $\mathbf{\%}$ \\
\hline Less than 120 & 1 & 3.57 & --- & --- \\
\hline $121-150$ & 7 & 25 & 1 & 3.57 \\
\hline $151-180$ & 11 & 39.28 & 9 & 32.14 \\
\hline $181-210$ & 8 & 28.57 & 10 & 35.72 \\
\hline $211-240$ & 1 & 3.57 & 6 & 21.43 \\
\hline More than 240 & --- & --- & 2 & 7.14 \\
\hline Total & $\mathbf{2 8}$ & --- & $\mathbf{2 8}$ & --- \\
\hline $\begin{array}{c}\text { Mean Duration of } \\
\text { Anaesthesia }\end{array}$ & $170.22(26.83)$ & $197.14(24.75)$ \\
\hline \multicolumn{4}{|c|}{ Table 5. Duration of Anaesthesia by Ist Dose } \\
of Local Anaesthetic \\
\hline
\end{tabular}

A statistically significant and progressive fall in pulse rate and blood pressure were noted in the first 10 minutes in CSEA group and in between 10 - 30 minutes in EA group. In EA group, the mean time for maximum fall in blood pressure was between 20 - 30 minutes and was comparatively more than in CSEA group.

\section{DISCUSSION}

The present study was carried out on sixty patients ranging from $15-70$ years of age. The patients were randomly divided into two groups- Group-I in whom combined spinal epidural anaesthesia was given and Group-II in whom epidural anaesthesia was used.

The doses required in epidural anaesthesia were higher to obtain proper sensory and motor blockade for surgery compared to the subarachnoid and combined spinal epidural. Our study was also similar to a study conducted by Rawal $\mathrm{N}$ et al. ${ }^{7}$ In the study, the mean value of dose of Bupivacaine in CSEA was significantly lower as compared to epidural anaesthesia ( $\mathrm{p}=0.0001, \mathrm{t}=40.10)$.

A statistically significant and progressive fall in pulse rate and blood pressure was noted in first 10 mins of CSE anaesthesia group and in between 10 - 30 mins of epidural anaesthesia group. This fall was noted because of autonomic nervous system blockade. In epidural anaesthesia group, the mean fall in blood pressure was between 20 - 30 mins and was comparatively more than in CSEA group.
When Bupivacaine is administered extradurally, the onset of action time ranges between 15 - 20 minutes (Ronald Miller, 1995). Patel et al ${ }^{8}$ used 0.5 Bupivacaine (hyperbaric) in CSEA and found mean time for onset of action to be $3.72 \pm 0.04$ minutes. These results are comparable to our study. In our study, the mean onset of sensory block was $3.16 \pm 0.875$ minutes in CSEA group, whereas $18.46 \pm 3.78$ minutes in epidural anaesthesia group. Blumgart $\mathrm{CH}$ et $\mathrm{al}^{9}$ showed that the mechanism of extension of spinal anaesthesia by extradural injection of local anaesthesia is largely a volume effect.

This study also reflected the shorter time needed for the action of local anaesthetic on motor blockade. The mean time of onset of motor block was $8.37 \pm 1.27$ minutes in CSEA group and $25.85 \pm 2.44$ minutes in epidural group, which is quite similar to Suzuki N et al.10 Statistically, the onset of action on motor blockade is significantly faster in CSEA group than in epidural anaesthesia group ( $\mathrm{t}=33.28$; $\mathrm{p}=0.0001)$.

The excellent and good analgesia observed in CSEA group and lesser grade of analgesia observed in epidural anaesthesia group correlates well with a study conducted by Rawal et al. ${ }^{7}$ In our study, degree of motor blockade was assessed by Bromage scoring system. Complete (score 10) and almost complete (score 6) motor blockade were seen in $78.6 \%$ of cases in CSEA group and in $64.6 \%$ of cases in epidural anaesthesia group, while partial block (score 3 ) and no block (score 1 ) was noted in $21.4 \%$ of cases in CSEA group and $35.7 \%$ of cases in epidural anaesthesia group. The findings are also correlated well by statistical analysis $(\mathrm{t}=11.73 ; \mathrm{p}=0.0001)$.

Mean duration of postoperative analgesia provided by 25 mg Bupivacaine and $50 \mathrm{mg}$ Tramadol in $10 \mathrm{~mL}$ given epidurally was $6.93 \pm 1.71$ hours in CSEA group and $7.92 \pm$ 1.93 hours in epidural anaesthesia because in both the techniques the method of postoperative analgesia was same, so the mean duration of postoperative analgesia could be the same. The findings are also confirmed statistically $(t=1.95$; $\mathrm{p}=0.004)$. These results are nearly similar to Baraka A et $\mathrm{al}^{11}$ and Lee et al. ${ }^{12}$

Bupivacaine is a comparatively longer acting local anaesthetic agent, which has duration of analgesia ranging between 75 - 180 minutes on intrathecal administration and between 150 - 300 minutes on extradural administration. These results are in accordance with Rudolf Stienstra et al.13 The concentration of local anaesthetic agent also affects the duration of analgesia. In this study, the mean duration of anaesthesia was $170.72 \pm 26.83$ minutes in CSEA group and $197.14 \pm 25.75$ minutes in epidural anaesthesia group. Statistically, the data is significant $(t=3.76 ; p=0.004)$. These results are nearly similar to those of Holmstrom et al.

\section{Incidence of Perioperative Complications}

In this study, hypotension and bradycardia were the most common complications seen in CSE anaesthesia group as well as in epidural anaesthesia group. This is similar to the results by Shaskey MC et al. ${ }^{14}$ Nausea and vomiting were also seen in study group. Incidence was equal in both groups.

In case of CSE anaesthesia and in 2 cases of epidural anaesthesia shivering were also seen probably due to vasodilation of peripheral vessels. 


\section{CONCLUSION}

1. Onset of sensory blockade is earlier in CSE than in epidural anaesthesia alone- the mean values are $3.16 \pm$ 0.87 mins and $18.46 \pm 3.78$ mins respectively.

2. Onset of motor blockade is also earlier in combined spinal epidural than epidural anaesthesia, the mean values are $8.37 \pm 1.27 \mathrm{mins}$ and $25.85 \pm 2.43 \mathrm{mins}$, respectively.

3. Duration of anaesthesia by first dose of local anaesthetic is slightly more in epidural than in combined spinal epidural anaesthesia. The mean value is $197.14 \pm 25.75$ mins and $170.72 \pm 26.83$ mins respectively.

A statistically significant and progressive fall in pulse rate and blood pressure was noted in first 10 mins of combined spinal epidural anaesthesia group and in between $10-30$ mins of epidural anaesthesia group and in between $10-30$ mins of epidural anaesthesia group. This fall was noted because of autonomic nervous system blockade. In epidural anaesthesia group, the mean fall in blood pressure was between 20 - 30 mins and was comparatively more than in CSEA group.

As evident from the study, the combined spinal epidural anaesthesia is better than epidural anaesthesia alone due to following reasons.

- Less doses of local anaesthetic drug is needed, so less chances of haemodynamic complication and tonic effects of the drug in CSEA.

- Onset of required degree of surgical anaesthesia is faster in CSEA.

- Postoperative analgesia can be given by epidural catheter in both combined spinal epidural and epidural anaesthesia.

- Incidence of intraoperative complications due to CSEA is very low.

\section{REFERENCES}

[1] Broadman LM, Mesrobian R, Ruttiman U, et al. Do anesthesiologists prefer a regional or a general anaesthesia for themselves? Reg Anesth 1986;11:557-3.

[2] Sitzman BT, Uncles DR. The effect of needle type, gauge and tip bend on spinal needle deflection. Anesth Analg 1996;82(2):297-301.

[3] Holmstrom B, Laugaland K, Rawal N, et al. Combined spinal epidural bloc versus spinal and epidural block for orthopaedic surgery. Can J Anaesth 1993;40(7):601-6.
[4] Tadoori P, Ravella R, Doss N, et al. Combined epidural spinal (ESP) anesthesia for caesarean section using lidocaine $1.5 \%$ with 1:200,000 epinephrine. Regional Anesthesia 1991;16(1):84.

[5] Niinai H, Nakagawa I, Hamada H, et al. Survey of combined spinal epidural anesthesia in Japananalysis of questionnaire from 148 hospitals. Masui 1999;48(3):295-300.

[6] Wakamatsu M, Ono $K$, Katoh $H$, et al. Effect of combined spinal and epidural anesthesia on blood loss during total hip replacement. Masui 1993;42(1):56-9.

[7] Rawal N. European trends in the use of combined spinal epidural technique-A-17 nation survey. Reg Anesth Pain Med 1995;20(Suppl 2S):162.

[8] Patel M, Swami A. Combined spinal-extradural anaesthesia for caesarean section. Anaesthesia 1992;47(11):1005-6.

[9] Blumgart CH, Ryall D, Dennison B, et al. Mechanism of extension of spinal anaesthesia by extradural injection of local anaesthetic. $\mathrm{Br} \mathrm{J}$ Anaesth 1992;69(5):457-60.

[10] Suzuki N, Koganemaru M, Onizuka S, et al. Dural puncture with a 26-gauge spinal needle affects epidural anesthesia. Anesth Analg 1996;82(5):10402.

[11] Baraka A, Jabbour S, Ghabash M, et al. A comparison of epidural tramadol and epidural morphine for postoperative analgesia. Can J Anaesth 1993;40(4):308-13.

[12] Lee CR, McTavish D, Sorkin EM. Tramadol. A preliminary review of its pharmacodynamic and pharmacokinetic properties, and therapeutic potential in acute and chronic pain status. Drugs 1993;46(2):313-40.

[13] Stienstra R, Dilrosun-Alhadi BZ, Dahan A, et al. The epidural "top-up" in combined spinal-epidural anesthesia: the effect of volume versus dose. Anesth Analg 1999;88(4):810-4.

[14] Sheskey MC, Rocco AG, Bizzarri-Schmid M, et al. A dose response study of bupivacaine for spinal anesthesia. Anesth Analg 1983;62(10):931-5. 